\title{
Lucian N. Leustean, The Ecumenical Movement and the Making of European Community
}

Oxford, Oxford University Press, 2014, 304 p.

Pascale Gruson

\section{(Q) OpenEdition}

\section{Journals}

Édition électronique

URL : http://journals.openedition.org/assr/27398

DOI : $10.4000 /$ assr. 27398

ISSN : $1777-5825$

Éditeur

Éditions de l'EHESS

Édition imprimée

Date de publication : 1 octobre 2015

Pagination : 326

ISBN : 978-2-7132-2515-4

ISSN : 0335-5985

\section{Référence électronique}

Pascale Gruson, « Lucian N. Leustean, The Ecumenical Movement and the Making of European

Community », Archives de sciences sociales des religions [En ligne], 172 | octobre-décembre, mis en

ligne le 27 mai 2016, consulté le 24 septembre 2020. URL : http://journals.openedition.org/assr/27398 ; DOI : https://doi.org/10.4000/assr.27398

Ce document a été généré automatiquement le 24 septembre 2020

(C) Archives de sciences sociales des religions 


\section{Lucian N. Leustean, The Ecumenical Movement and the Making of}

\section{European Community}

Oxford, Oxford University Press, 2014, 304 p.

\section{Pascale Gruson}

\section{RÉFÉRENCE}

Lucian N. Leustean, The Ecumenical Movement and the Making of European

Community, Oxford, Oxford University Press, 2014, 304 p. 
1 En novembre 1990, soit un an après la chute du Mur de Berlin et un an avant la signature du Traité de Maastricht, le président en exercice de la Commission européenne, Jacques Delors, s'adressant à un parterre composé de représentants des Églises protestantes et anglicanes et de fonctionnaires des institutions européennes, exhortait ceux-ci à compléter les structures communautaires déjà établies en leur donnant « un cœur et une âme ». Mais quelle était la visée de son propos? S'agissait-il d'associer plus activement le monde religieux aux travaux des institutions européennes? Ou s'agissait-il de préciser plus clairement ce que pouvait être leur registre d'intervention et les limites de leur compétence (se concentrer surtout sur le

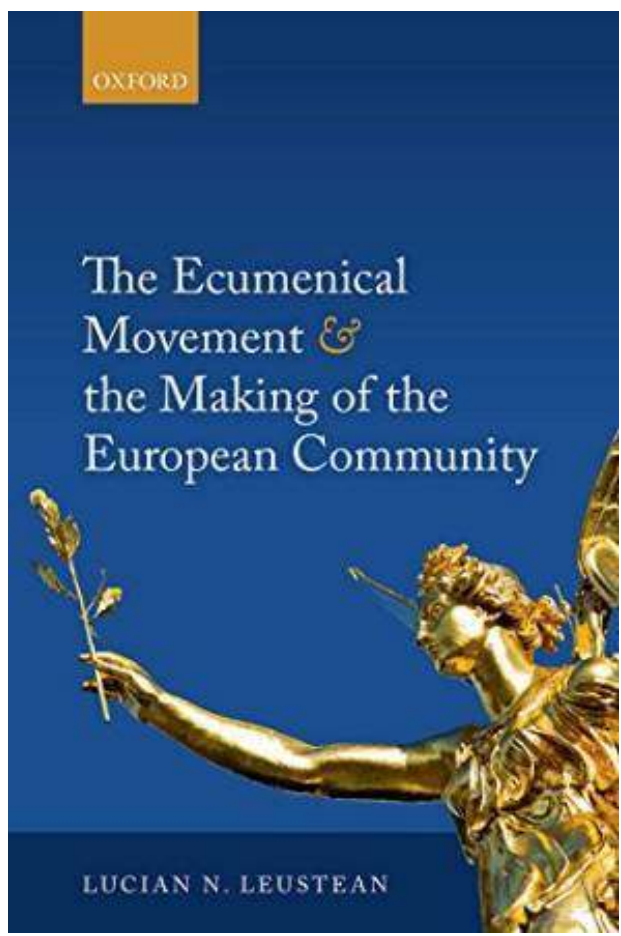
«supplément d'âme ») ? Si cette question a pu être posée, c'est que la réflexion active des églises sur la construction européenne était de fait engagée depuis longtemps dans les coulisses de la Commission et avait donné lieu à plusieurs prises de position déjà dont certaines avaient pu être assez critiques. Elle avait commencé, à l'initiative du député socialiste et protestant convaincu, André Philip, et du Conseil œcuménique des Églises, dès la mise en place de la Communauté européenne du Charbon et de l'Acier en 1950. Son propos était alors d'associer des hommes d'Église, des laïcs engagés, des fonctionnaires de la communauté dans une réflexion sur les enjeux de la construction d'une Europe réconciliée, sur les choix possibles de développement de cette coopération, sur les responsabilités à prendre au sérieux dans un monde en transformation.

2 En proposant une histoire du souci européen que les Églises protestantes et anglicanes ont donc très vite porté dans des termes qui rejoignaient ceux d'un engagement citoyen actif, Lucian Leustean suggère de passionnants sujets de réflexion dont la dimension éthique n'est pas toujours bien connue du public français.

C'est en tout cas très naturellement et dans la suite de la réflexion et de l'action œcuméniques qu'elles avaient menées sur plusieurs fronts dans l'entre-deux-guerres, que les Églises protestantes et anglicanes ont d'emblée porté une grande attention au projet de réconciliation européenne de Robert Schuman et du Chancelier Adenauer. Les mouvements œcuméniques protestants de l'entre-deux-guerres, portés entre autres par la Fédération universelle des associations chrétiennes d'étudiants, avaient nourri, il faut le rappeler, une forte opposition au nazisme, notamment dans le cadre de l'Église confessante. Ils s'étaient engagés dans une résistance civile. En 1948, la création du Conseil œcuménique des Églises organisait leur coordination, reconnaissant ainsi la nécessité d'approfondir une réflexion critique sur les orientations du monde qui nous est commun et sur ses obscurités, de prendre en considération la dimension éthique à laquelle les décisions politiques sont souvent confrontées. 
Lorsque André Philip, avec Paul Abrecht, engage le COE en 1950 dans une action auprès des instances européennes nouvellement créées, il s'agit bien pour lui de ne pas ignorer les dimensions économiques et techniques de la construction européenne, de les comprendre, et de réfléchir sur leurs implications. Mais 1950, c'est aussi le temps de la Guerre froide, le développement de l'OTAN, le problème des rapports entre l'Europe occidentale et l'Europe de l'Est. C'est dire qu'au sein de cette jeune "Commission œcuménique pour la coopération européenne ", des analyses très différentes de ces données, des perspectives divergentes sur ce que doit être l'Europe réconciliée se font jour. Mais aucun participant ne souhaite conclure trop vite ou ne se conformer qu'à une seule ligne directrice. Les débats sont sans concession, mais ouverts. Relayés par des instances du Conseil de l'Europe à Strasbourg, par la commission des affaires internationales de la Fédération protestante de France, du conseil de l'Église anglicane, ils progressent. Peu à peu, l'ambition de faire reconnaître plus officiellement une instance œcuménique par la Commission européenne se fait jour et au début des années 1980, cela devient une réalité. La nouvelle « commission œcuménique pour les églises et la société dans la Communauté européenne" rencontre sans doute des raideurs bureaucratiques. Mais à Bruxelles, à Strasbourg ou au Luxembourg, un élan a été donné et d'autres groupes de réflexion oecuménique se sont constitués, y compris, depuis Vatican II et la création du Conseil pontifical pour la promotion de l'Unité des chrétiens à l'initiative de l'Église catholique. Tous associent responsables d'églises et laïcs engagés dans un travail commun.

5 Lucian Leustean conte la chronologie détaillée de cette histoire de manière haletante. L'évolution des sigles qui tracent les avatars du groupe fondateur et ses multiples embranchements pourrait même être vertigineuse. Il y a les fortes personnalités en nombre. On voit aussi comment les débats au sein de l'Église anglicane ont été importants pour les négociations qui ont abouti à l'entrée du Royaume-Uni dans le Marché Commun. D'une manière générale, l'auteur sait montrer les progrès et les reculs des échanges, leurs ouvertures ou au contraire leurs replis dénués d'ambition, les frilosités nationales. Mais il sait montrer aussi que ceux qui sont engagés dans l'Église peuvent prendre au sérieux et dans ses dimensions politiques et sociales fortes, la modernité de notre présent.

6 Ce livre est dédié à la mémoire d'un grand résistant allemand, Adam von Trott zu Solz qui fut l'un des membres les plus actifs du complot contre Hitler et fut de ce fait condamné à mort. Il avait souvent rencontré, dans ses activités de résistance, Willem Visser't'Hooft, le premier Secrétaire général du Conseil Ecuménique des Églises. Ils avaient partagé l'exigeante espérance d'une Europe réconciliée. 